\title{
Ethical Professional Writing in Social Work and Human Services
}

\section{Donna McDonald, Jennifer Boddy, Katy O’Callaghan, Polly Chester}

Donna McDonald, BA, BSW, MA, PhD. Senior Lecturer \& Convenor Disability Studies, Griffith University, School of Human Services and Social Work, Griffith Health Institute, Population and Social Health Research Centre. Email: donna.mcdonald@griffith.edu.au.

Jennifer Boddy, PhD, Senior Lecturer in Social Work, Griffith University, School of Human Services and Social Work, Griffith Health Institute, Population and Social Health Research Centre. Email: j.boddy@griffith.edu.au

Katy O’Callaghan, BA MSWAP, Director, Outpost Consulting. Katy is a researcher, writer and social policy analyst. Email: katy@outpostconsulting.com.au

Polly Chester, BSW. Research Assistant, School of Human Services and Social Work, Griffith Health Institute, Griffith University (Logan campus).

Email: p.chester@griffith.edu.au

Correspondence should be addressed to:

Donna McDonald, PhD

School of Human Services and Social Work, Griffith Health Institute, Griffith University, University Drive, Meadowbrook Q 4131 Australia

Telephone: 0733821176

Facsimile: 0733821210

Email: donna.mcdonald@griffith.edu.au 


\section{Ethical Professional Writing in Social Work and Human Services}

Abstract

Social workers write a lot and their writing has a major impact on people’s lives. The complexity of their writing task arises because they must deal with confidential client information while usually writing for multiple audiences. This means that social work students must achieve more than the basics of technical writing skills.

The purpose of this article is two-fold. First, after reviewing the literature on the importance and challenges of writing well in social work (and having hosted a number of writing workshops for social workers and human services practitioners), we argue that the development of writing skills must be framed within the evolving social, political and ethical professional circumstances of the present, and provide a metacognitive framework that assists in responding reflexively to the unknown context of the future. By highlighting how ethical decision making models can be used to develop reflective capacity and teaching writing skills through the lens of the profession's ethics and values, students will be instilled with a greater understanding of the importance of writing.

Second, we propose a model of ethical professional writing which integrates three essential elements: reflective mindfulness of the client-centred focus of writing responsibilities; a sound understanding of the values and principles of the social work and human services professions as highlighted in the unifying themes in various codes of ethics; and competence in compositional, rhetorical and technical writing skills. In particular, this article focuses on the second element of this model which is concerned with having a sound understanding of the values and principles of ethical professional writing. We conclude that this framework will promote writing competence and benefit clients.

\section{Keywords}

Ethical professional writing; client-centred writing; writing values and principles 


\section{Ethical Professional Writing in Social Work and Human Services}

A great writer has a high respect for values.

André Maurois, The Art of Writing

We all write. While writing is a crucial daily activity for social workers, the issues identified in this article are relevant to all professions who serve people in their core role. On any given day at work, we might write emails, reports, letters, and briefs for our managers, case file notes, case plans, funding applications, submissions, and so the list goes on. The single unifying feature of all that writing is its subject: "the client”. That client might be a whole population cohort such as people with disabilities in need of support services or Indigenous peoples living in remote areas; children at risk of family violence; migrants seeking access to health services; or the client might be a single individual—perhaps the next person on the “must contact” list.

If our observations, judgments and recommendations are not clearly conveyed in our writing, serious repercussions can—and do—arise for our clients. Social workers must write well to pursue social justice with competence and integrity. Indeed, mindfulness in how and why we write as well as what we write reflects our commitment to the values and ethics of professional practice.

Despite agreement in the literature about the importance of writing (see Bender \& Windsor 2010; Cuthbert \& Spark 2008; Healy \& Mulholland 2007; Heron \& Murray 2004; Luiselli 2010; Malekoff 1999, 2006; Staudt et al. 2003; Steinberg 2007), our experience tells us that students are still graduating without the overall writing proficiency to equip them for the breadth of professional situations they are likely to face. While the acquisition of technical writing skills provides a basis for a degree of grammatical proficiency, students need more than this. 
After reviewing the literature on why writing is important in social work and why it is difficult to do (and having hosted a number of writing workshops for social workers and human services practitioners), we argue that in addition to the technical framework which is most often used, writing skills must be taught within the framework of contemporary social, political and ethical professional circumstances. Social workers work within the context of a prescribed set of ethics, values and responsibilities. We therefore propose a model for ethical professional writing which recognises that teaching writing skills through the lens of the profession's ethics and values will instil students with a greater understanding of the weight of responsibility they bear for their clients every time they write, even if it is just a one sentence email written in haste.

\section{Why Good Writing Matters in Social Work and Why it is Difficult to Do}

Social workers tend to think of themselves as "people people” and most understand the importance of verbal communication. They also write a lot and their writing has a major impact on people’s lives (Dunlap 1997; Glicken 2008). One study found social workers spent between 15 and 20 per cent of their time on writing tasks (Carney \& Koncel 1994). They write in several genres including formal documents such as annual reports, grant proposals and program evaluations; marketing materials such as brochures and descriptions of services; organizational guides such as agency manuals; academic portfolios including lecture notes, conference presentations and journal articles; as well as social work records and case notes. Much of this writing, particularly agency documentation, tends to be seen as an administrative task, an unnecessary burden or a necessary evil, and is resisted by many social workers (Cumming et al. 2007; Gelman 1992; Waller et al. 1996).

Carney and Koncel (1994) note that social workers' writing is the major mode of communication about a client to clinicians, insurance companies, courts and government 
agencies, and it stays in the client’s record for life. Falk and Ross (2001) state, “Social workers who can write a well-constructed report, a clear description of a client, or a persuasive memorandum or letter are more effective at serving the interests of their client” (p. 125) and all those who are working to assist that client.

Significantly_ —and this is not always sufficiently understood by novice or even experienced social workers—-those social work reports do more than "communicate”. They also have the power, long past their original purpose, to shape the lives of people (D'Cruz, 2004). Social work reports not only address their intended audiences in a particular (and perhaps local) organization for a specific purpose in the immediate present, but they also have the potential to reach unintended, unforeseen audiences in entirely unpredictable circumstances across vast geographies of space, even many decades later. Consider, for example, those historic, damning case file notes written in the twentieth century about Aboriginal Australian children stolen from their families (HREOC 1997), or about babies forcibly taken for adoption from their young mothers even while they were still in hospital (see Australian Government Senate Community Affairs References Committee 2012). Case file notes are powerful. Words written in administrative haste or case-load fatigue may result in carelessly consigning the prospects of a client to an unforeseen fate. While approaches to ethics and values change over time- - for example from a paternalistic to a rights based approach (see McAuliffe, 2014) — and there are questions around the universality of values and ethical theories (Banks, 2008), social workers can use ethical professional writing guidelines as a safeguard to protect vulnerable people against human rights abuses.

Alter and Adkins (2006) assert that writing has never been more important for professional social work: 
[I]t is not overly dramatic to say that the lives of clients can be significantly diminished by a social workers’ inability to write well, or significantly enhanced by strong writing proficiency in social workers (p. 493).

Organisations and agencies are increasingly required to respond to risk and high levels of accountability (Cumming et al. 2007; Gelman 1992; Oglensky \& Davidson 2009). In a review of social worker documentation practices in a hospital, Cumming et al. (2007) concluded that written communication is an area of potential ethical risk and needs to be seen as an "integral part of clinical practice and not an administrative side-task" (p. 254). Foundational ethical knowledge is essential for navigating situations where boundaries between managerial accountability, legal risk and ethical responsibilities are unclear. Consistent use and sound understanding of codes of ethics assists practitioners in overcoming legal risk and managing competing demands by providing guidelines for acting in an ethically responsible manner and maintaining pursuit of the profession's aims. This includes, and is not limited to, carrying out the aims and intentions of organisations and management responsibilities alongside strong allegiance with social work codes of ethics, and acknowledging that at times, there may be discord between them due to differences in value positions.

Language must be precise to avoid misconceptions. These misconceptions can be perpetuated over a person's lifetime. This was illustrated during one of our ethical writing workshops when an example of careless writing (and it has to be said, careless reading by subsequent social workers; the task of responsible reading is a prospective area for further research) was provided by an Australian child protection worker as follows:

A social worker describing a family situation noted in her case notes that a "touching event” had occurred between a 12 year old boy and his 10 year old stepsister. However, when that boy was 14 years old, a new social worker was called to the 
family home for an entirely different reason, and in writing up her case notes referred to the event of two years earlier as "sexualized behavior". A visit by a third social worker a further two years later resulted in the boy’s records being updated to label him as a "sex offender" based on her reading of the one "touching event" recorded four years earlier. The boy, by now 16 years old, was forbidden to be left alone with his 14 year old sister-even though no further comment or complaint about “touching”, let alone “sex offences”, had been made by any family member (Author. Child Protection Workshop notes, 16 May 2012).

Even simple documentation tasks are not necessarily managed well by social workers. Social work records have been found to contain contradictory opinions, crude judgments, rumours and unsubstantiated allegations (Gelman 1992). This was demonstrated in one of our ethical writing workshops, where an Australian child protection worker described an incident where the social worker had not described his or her observations in an objective manner: A report to the Child Safety Department from a community agency referred a family to the Child Safety Department on the basis that the family's home was 'a cess-pit' and 'unhygienic'. Upon reading the report, a Departmental case worker decided to visit the house to ensure the children living there were safe. The case worker discovered that, while the house needed some maintenance and was somewhat untidy due to the presence of three young children, there was no evidence that it was unclean or unsafe (Author. Child Protection workshop notes, 16 May 2012).

While clients are the main beneficiaries_or unintended victims_of social workers' writing, writing also provides an opportunity for learning and influencing professional practice through the publication and dissemination of research (Author 2012; Heron \& Murray 2004). Scholarly writing by social workers allows those who work directly with clients to have a voice in academic and policy debates (Heron \& Murray 2004). 
As well as being important to the client and the profession, the practice of writing brings professional benefits to the writers themselves. Writing can help social workers develop a professional identity and learn the ropes of the job through the processes of information gathering, hypothesis generation, analysis, evaluation and reflection (Oglensky \& Davidson 2009). This professional socialisation happens through "the acquisition of values, attitudes, skills and knowledge pertaining to a professional subculture” (Page 2005, p. 1). Miller (1991) extols the role of writing in professional socialization, whereby the individual must learn the common sense of the professional community ... such practical awareness is particularly essential to learning how to talk and write like a professional (p. 58).

Miller says professional writing is about "constructing shared knowledge” and allows the writer to "question and act on shared problems through language”. It is a means of “reflecting on oneself and acting on one’s world” (p. 69).

At the same time, Miller chafes at "the limitations of formulaic approaches to written products and processes ... outside the classroom” (p.58). He astutely observes that "problems and audiences have histories and the novice [student writer] cannot easily draw on the shared practical wisdom that the community has developed to address such problems” (p. 58). Miller’s complaint about "formulaic approaches” strikes at the nub of the issue.

\section{Essential ethics education: developing a metacognitive framework for ethical professional writing}

Effective writers need more than grammar. They need the reflexive mindset of ethics, values and accountability to transform their writing from a paper-based product to a dynamic process that best serves their clients. Banks (2008) asserts that the term "social work ethics" 
encompasses a specialist area of professional ethics, and includes study of the norms of justice-oriented action, and specifics of character and values that pertain to the nature of 'living the good life' that are embraced and demonstrated by social workers.

Introducing students to an ethical decision making model as a precursor for ethical professional writing encourages the development of good habits in applying social work ethics to contemporary social, political and professional ethical circumstances. McAuliffe and Chenoweth’s (2008) Inclusive Model of Ethical Decision Making provides a metacognitive framework to help students understand how to integrate social, political and ethical knowledge into their professional practice, which in turn provides a foundation from where ethical professional writing can flourish. Ethics content is a foundational aspect of social work education, and while values and ethics always have been a part of social work education, ethical knowledge and standards have significantly expanded in recent years (Reamer, 2012).

The foundation of the Inclusive Model of Ethical Decision Making is built upon four essential platforms of social work practice: accountability, consultation, cultural sensitivity and critical reflection (McAuliffe \& Chenoweth, 2012). Accountability encourages openness, transparency and honesty, and includes the ability of the worker to take the broader social context into account. Consultation pertains to the action of using the counsel and wisdom of others wisely, and encourages discussions with others in the interests of upholding professional integrity. Cultural sensitivity commands respect for the worldviews of others and encourages culturally sensitive responses in order to circumvent discrimination. Critical reflection exhorts workers to open up their thinking processes to the scrutiny of others, providing an avenue to improve practice (McAuliffe \& Chenoweth, 2008). This higher-order model of professional ethical decision making is consistent with, and informs, the values and principles of ethical professional writing. 
The core values and principles of reflexivity, sensitivity, responsiveness and critical reflection provide an all-purpose framework for social workers to use when appraising what is happening in the here and now, and the mindset for making sound decisions about the nature of the ethical professional writing that would follow. The steps of the decision making model include: (re)defining the ethical dilemma, (re) mapping legitimacy, (re)gathering information, alternative (re)approaches and action and critical (re)analysis and (re)evaluation (McAuliffe \& Chenoweth, 2008). Varying combinations of these steps can be incorporated into the ethical professional writing process at any stage and as frequently as required, to guide practitioners during the writing process and keep them on point.

Banks' research on the use of ethical decision making models purports that there is often insufficient time in practice to consult a step-by-step model such as the Inclusive Model of Ethical Decision Making, and that these kinds of models are not practical for use on a daily basis. Nevertheless, they are effective ways of encouraging students to reason and reflect in a systematic capacity on ethical issues in practice, in the hope that elements of these models will become intuitive and instinctive in contemporary practice setting. Similarly, Hugman (2005) argues that the goal of social work ethics education should be to establish a framework for practice whereby fledgling practitioners are encouraged to embrace the moral nature of practice and the ambiguities inherent within it.

Any kind of social work ethics education involves attempting to teach about things that do not yet exist as they are created in action (Hugman, 2005). However, inductive frameworks such as our proposed model of ethical professional writing can be used to prepare or rehearse ways for responding to the ambiguity of contemporary social, political and professional ethical circumstances. 


\section{The Importance of Ethical Professional Writing}

The need for more effective teaching of writing during undergraduate and graduate degree programs is a long-held concern. Over two decades ago, Simon and Soven (1990) found evidence of writing deficiencies amongst social work students and practitioners, and they advocated the inclusion of more and different writing instruction in social work programs. In 1992, Reynolds et al. also suggested writing instruction in a variety of forms for social workers so they can "become more fully aware of rhetorical situations and navigate their inherent complexities” (p. xvi). In 2001, an American survey of staff in 21 social work schools found a significant proportion of social work students lacked the writing skills to carry out their social work responsibilities effectively (Falk \& Ross 2001). Other researchers in the United States have noted a decline in writing skills amongst social work students and that the lack of focus on writing skills has been a gap in their professional training (Alter \& Adkins 2001; Oglensky \& Davidson 2009; Waller et al. 1996).

A 2004 survey by Carney and Koncel found that social workers struggled with three particular writing challenges: working with confidential information; producing under tight time constraints; and writing for multiple audiences. Their most difficult tasks were assessments, letters and evaluations where all three challenges have to be balanced concurrently. Social workers also reported their difficulties in exercising discretion about the client's best interest when deciding what to include in letters to advocate for the client without harming the therapeutic relationship or revealing information that might be potentially harmful to clients; and what language to use to convey subtle nuances of a client's character and the complexities of their life. The survey respondents said the easiest tasks were short, formulaic, and objective, or written to a single audience such as case records (Carney \& Koncel 1994). However, there is no such thing as a single audience. Social workers need to understand "the tensions and complications that results when almost 
everything they write will have multiple audiences, purposes and uses” (Reynolds et al. 1992, p. 2).

Most professional writing courses are based on the foundation skills of grammar. In this way, the focus for developing writing skills is on the "how" of writing, rather than the "why” of writing. Thus, the technique and technology of writing are emphasised rather than the rationale, benefits or consequences of effective writing for clients. Such an approach ignores the legal, political and ethical dimensions and implications of writing. As social work educators, we have observed that students are unaware of the impact of their writing - for better or worse- on their clients. Even when students have at least a passing familiarity with the foundation skills of grammar, many appear insufficiently mindful of the values and principles underpinning professional writing. A study of 24,000 US undergraduates by sociologists Arum and Roksa (2011) supports this observation. Their study found a loss or diminishment of skills in writing, cultural awareness, political participation and critical thinking by students.

Oglensky and Davidson (2009), who contend that "the process of mastering a clinical writing genre also requires students to understand and employ essential professional thought processes, practices, and norms” (p. 139), designed a writing course for social workers that combined practical writing skills with their professional values. Their model is underpinned by two concepts, which have been drawn from several disciplines: understanding various types of written records as different genres of writing; and understanding the process of record writing as a situated learning experience that supplies students with a cognitive apprenticeship. Their model uses a series of genre-based rubrics as frameworks for professional record writing, and employs experiential learning techniques, rather than simply teaching students about the importance of writing (Oglensky \& Davidson, 2009). Their approach was to strengthen writing ability while simultaneously promoting habits of thinking 
and practice that instil professional identity and discipline in students who will soon be employed as social workers.

A similar approach was used by Falk and Ross (2001) who developed a framework that integrates "instruction on writing with acquisition of social work knowledge, values and skills and the development of the professional self” (p. 125). Their Integrative Approach lists nine purposes of writing for social workers - to describe, to analyse, to be accountable, to persuade, to understand and care for the self, to communicate the self to others, to understand the perspective of others, to participate in knowledge building and to represent the profession to society, and links these with writing and social work skills. For example, one purpose of writing is to "understand and care for the self" (p. 127). This can be practised through reflective writing, personal journaling, and free writing. Such a process would assist writers with getting started with writing, overcoming barriers to writing, writing freely, and selfknowledge. Falk and Ross (2001) say this approach helps students see the centrality of writing to social work. "It puts writing at centre stage, demanding attention, practice and mastery” (p. 139).

\section{Our Approach to Ethical Professional Writing}

Similar to Falk and Ross who identify a relationship between writing and the acquisition of social work knowledge and values, and like Oglensky and Davidson who note the different purposes of different writing genres, we believe that a values-based approach to writing is the pathway for improving students' professional writing skills. However, we depart from Oglensky and Davidson who focus exclusively on report and record writing in medical and hospital settings using a model which, as they themselves acknowledge, is complicated and difficult to retain. 
Our model focuses on a broad range of practice settings (both government and nongovernment) and writing genres, with the focus on the application of values and principles rather than the genre itself. Unlike Falk and Ross, whose emphasis is upon "mastery” of skills, our approach is based upon the principle that client-centred mindfulness, rather than the task of writing itself, needs to be the focus of writing instruction. We emphasise mindful reflection of social work's ethical values and principles as an essential core element for proficiency in writing because we have observed that even when students know how to apply their grammatical writing skills proficiently, they often still do not fully comprehend the potent consequences of their writing style and content for clients.

In building on the work of Falk and Ross (2001) and Oglensky and Davidson (2009), we turned to the core values and principles of practice as outlined in various social work codes of ethics, including in Australia (AASW 2010), USA (NASW 2008), Britain (BASW 2012), Canada (CASW 2005) and New Zealand (ANZASW 2008), as well as the International Federation of Social Workers (IFSW 2004). Core values emerge, including social justice, respect for human rights, dignity and worth, and integrity. Other key principles discussed in social work literature and codes of ethics include reflexivity, authenticity, and sensitivity. Our model also recognizes the importance of purposeful writing, taking into account these values and principles, particularly as it relates to writing persuasively for the benefit of clients.

Our model of ethical professional writing seeks to combine an understanding of the different genres of writing and their purposes (Oglensky \& Davidson) with specific guidance about writing that is informed by social work knowledge, skills and values, and professional development of the self (Falk \& Ross, 2001). We achieve this by using an ethical values and principles based framework derived from social work codes of ethics to underpin all pieces of ethical professional writing. Regardless of the audience or genre of writing and organisational 
context, we emphasise that the approach to writing should not change, as it ought to always be underpinned by awareness - informed through the prism of an ethical decision making framework - of the tensions and implications of the changing context of contemporary social, political and ethical professional circumstances.

The different criteria for effective writing in the genres of composition, journalism, technical and professional writing stem from the shift of emphasis in certain skills from one discipline to another. Composition with its liberal arts tradition focuses on rhetorical skills, including the five canons of rhetoric, invention, arrangement, style, memory and delivery. These rhetorical skills are said to provide a broad, ethical, values-based foundation (Miller 1991; Spigelman \& Grobman 2006) and would be particularly important to social workers involved in persuasive writing and advocacy. Technical writing tends to focus on organisation, clarity, conciseness and accuracy (Solomon 2004) as well as basic skills such as good grammar and revision. Other professions call for a broader and more interdisciplinary focus for writing programs, bringing together the rhetorical and the practical skills needed by writers in the workplace (Spigelman \& Grobman 2006).

We propose that the unifying values and principles in the various codes of ethics must be integrated with the necessary skills for proficient writing in order to establish the foundations of ethical professional writing. Thus, ethical professional writing by social workers_-and all professionals who serve people-rests on the integration of three essential elements: reflective mindfulness of the client-centred focus of writing responsibilities; a sound understanding of the values and principles of the social work and human services professions as highlighted in the common themes across the various codes of ethics; and a sound competence in compositional, rhetorical and technical writing skills. Exercises used within our program illustrate these three elements. In the following section, we illustrate how this relationship works by examining each value and principle in turn. 


\section{Values and Principles}

Social justice. Social justice is central to social work practice and must underpin all writing in social work. Social workers must "promote social justice, in relation to society generally, and in relation to the people with whom they work" (IFSW 2004). Thus, social workers should use writing to challenge injustice and unhelpful status quos, particularly as it relates to policies and practices. With a sound understanding of social work ethics, students can infuse their ethical professional writing with social justice regardless of the genre of writing. Writing can be used as a tool for social change, by connecting with an audience, advocating for clients, critically reflecting on practice (Ellman et al. 2012), drawing attention to pressing social needs and pushing for anti-oppressive policy changes (Adamek 2011). Thus, developing student skills in writing of all kinds can help strengthen their commitment to and fight for social justice (Epple 2010).

According to Wronka (2008), social justice can act as a framework for writing and practice interventions. This means that social workers in their writing should challenge negative discrimination and recognise diversity by using language that is inclusive and does not further stigmatize already marginalized people. As a participant in one of our workshops on ethical professional writing said, "Descriptors such as ‘selfish’ or 'lazy’ are crudely judgemental and need to be avoided, particularly as the people concerned have a right to read their files". However, writing from a social justice framework means more than carefully selecting words. It also involves openly valuing clients’ lived experiences, being critically reflective, connecting with the audience, and drawing attention to social injustices to advocate for social change. This may be challenging and requires students to openly engage in critically reflexive practice and supervision to tease out the distinction between description (which is an objective account of events) and interpretation (which is a subjective account of 
events). Early discussion and critical reflection on students' tendencies to interpret rather than describe promote self-awareness around judgmental behaviours that may have a negative impact on ethical professional writing.

Respect for persons. Respect for human rights, dignity and worth is a cardinal social work value and is captured in all Codes of Ethics. For example, the International Federation of Social Workers (IFSW) Statement of Principles states: "Social work is based on respect for the inherent worth and dignity of all people, and the rights that follow from this". This principle is reflected in the social work value of acceptance, which combines "a recognition and endorsement of the other's autonomy (his or her own separate views, goals, feelings, experiences, and capacity to act) with a feeling of affiliation with or connection to him or her” (Berlin 2005, p. 483).

Berlin (2005) says acceptance reminds social workers to minimise the controlling aspects of their interactions with clients and to "work toward resolutions that are meaningful to the client and in the service of his or her most deeply held goals” (p. 483). Linked to acceptance is the concept of respect. Respectful relationships with clients are those in which the client is cared for but also allowed to be different and self-determining (Sennett 2003). In writing, the values of acceptance and respect for both the reader and the subject of the writing can be demonstrated by the language used. All language is embedded within particular social systems and most language is infused by ideology. Accepting and respectfullanguage would be non-gender specific, culturally inclusive, and would not be judgemental. The tone of the writing would be open; not condescending or controlling. The following exercise is used with students to help them to begin thinking about how respector lack of it—can affect clients. Students are invited to be mindful of the language they use in writing.

A social worker in writing up case notes about a client who had not turned up for 
some appointments described the client as "lazy" and "selfish". The client asked to read the case notes and was given access in line with organisational policy and Freedom of Information laws. She was shocked to read the description of her behaviour and declined further assistance from the organisation. From then on, she was reluctant to seek assistance from any services.

- What other words (or support strategy) could the social worker have used to show more acceptance and respect?

- What longer-term impact could this lack of acceptance and respect have on the client and future services to client?

Professional integrity. Most codes of ethics discuss the importance of operating with integrity (see for example, BASW 2002; AASW 2010; CASW 2005; NASW 2008), with the IFSW explicitly stating that "social workers should act with integrity". This involves being mindful of organisational requirements and legal obligations. It also means being mindful of professional boundaries and responsibilities. One incident was described to the research team where a mental health social worker in writing an assessment about a client wanted to impress the other staff reading the assessment with her knowledge of psychiatric conditions. Rather than describing what she saw of the client's behaviours, she presented a diagnosis of the behaviour using psychiatric terminology. Such an approach is problematic and does not reflect the requirements of the profession around integrity. This incident is used in an exercise described below to highlight the importance of both authenticity in writing and professional integrity.

A mental health social worker in writing an assessment about a client, wanted to impress the doctors and nurses reading the assessment with her knowledge of psychiatric conditions. Rather than describing what she saw of the client's behaviours, she presented a diagnosis of the behaviour using psychiatric terminology. 
- What are the dangers of using language outside your expertise?

Closely aligned with this value is the need to be accountable and transparent in writing, and thus writing with accuracy, judiciousness and credibility.

Accountability and transparency. The need to be accountable is featured in all social work codes of ethics, being repeatedly stipulated as a requirement of practice. For example, "Professional accountability requires members to maintain accurate client records, and to take all reasonable steps to ensure the confidentiality of this information" (ANZASW 2008, p. 4). Accountability has been described as liability to "being called on to give an account of what one has done or not done” (Banks, cited in McAuliffe \& Chenoweth 2008). Accountability is linked to being open, transparent and honest (McAuliffe \& Chenoweth 2008). To be accountable, social workers need to clearly articulate and justify their decisions, while taking into account the broader social context in which they operate.

Transparency is related to accountability and according to the CASW (2005) "Social workers value openness and transparency in professional practice” (p. 7) including with their clients and other stakeholders. Sharing records with clients in an open and direct way is one way social workers can be transparent and accountable to their clients. It has been shown to overcome much of the hostility that has traditionally been directed at the social services (Gelman 1992). Transparency is said to help to lessen the distance and power differential that may exist between the worker and the client. Transparency is improved by giving clients information and involving them in decisions (Gray et al. 2009). Increased access to information over the internet and the evidence-based practice movement is encouraging greater transparency of what is done and its effects (Gambrill 2001).

Accuracy in recording and the ability to produce a fair representation of a clients' point of view is important for transparency and accountability. Quality record keeping ensures the accountability not only of workers to their clients but also of workers to their 
employers, and organisations to their funding sources (Gelman 1992). In our approach to teaching ethical professional writing, students are invited to reflect on the AASW Code of Ethics — described in the example below — and show how the requirement to be accountable and transparent, while being mindful of the need for confidentiality and care, can be evident in their writing.

Read through the AASW Code of Ethics (2012). Consider the following principle: Open, accountable, transparent, collaborative and inclusive of the relevant stakeholders in the decision- making process, while observing appropriate confidentiality and duty of care requirements

- How can you ensure your writing reflects this principle?

- What are some of the challenges you might encounter in implementing this principle?

Accuracy, judiciousness and credibility. Social workers need to discover full and accurate information about clients' circumstances and accurately record the information to give a clear understanding of their needs to other professionals working with those clients. The AASW Code of Ethics (2010) states that,

Social workers will record information impartially and accurately, taking care to: (i) report only essential and relevant details; (ii) refrain from using emotive or derogatory language; (iii) acknowledge the basis of subjective opinions; (iv) protect clients’ privacy and that of others involved in the situation (p. 29).

Thus, records must be useful and accurate to minimise risk and exposure to liability claims (Gelman 1992) and writers must be careful about using personal codes in case notes. For example, as one practitioner described in a workshop, "I read a case note that used the abbreviation 'BP' to describe a client's condition. This could have meant any number of things about this client, each requiring different responses-Borderline Personality, Bipolar 
Disorder, Blood Pressure..." Misunderstanding what was meant by "BP” could have had serious consequences for the client. A further example was described to the research team where an acute care team used a whiteboard to communicate key information about clients to the next shift. Under the comments for particular client, the action was documented as "close follow-up”. The team interpreted this to mean cease servicing and close the case. However, the intended meaning was to provide active support and closely monitor the client. Accuracy in writing means there are no errors, including errors of fact, number, or date, nor any incorrect grammar, punctuation, vocabulary or spelling and correctly acknowledging and identifying sources.

Accuracy in writing also requires judiciousness; ensuring that writing is, “done with good judgment or sense” (Oxford English Dictionary). Social work is complex and issues are rarely straight-forward. Social workers are constantly required to exercise their judgment when making decisions about what is ethically right or wrong, and what is in the best interests of their clients. In designing writing assessments for social workers, Oglensky and Davidson (2009) say the most complex writing skills are those related to "the overall 'sensemaking' function” (p. 147). They say that being able to “add up” information within the clinical logic of each field is a complex business:

The professional must evaluate the material specific to the case, while taking into account disciplinary knowledge, theory and expertise regarding what it means . . the student must learn to put the pieces together, identify patterns, prioritise concerns etc. (Oglensky \& Davidson 2009, p. 147).

Credibility combines the elements of trustworthiness and expertise, and is underpinned by accurate, clear and transparent writing. It is defined as the quality of being believable or trustworthy, worthy of confidence, reliable (Collins Concise Dictionary). According to Harper and Lantz (1996), a client may assign credibility to a social worker 
because of his or her education position, role, age, gender and other factors over which the practitioner has little control. Credibility can also be achieved when clients have favourable experiences with social workers that foster respect, confidence trust and hope (Hepworth, et al 2010). In writing, credibility is about having faith in the competence of the writer. This requires using reliable information, getting the facts right and providing complete information. It is also about being consistent in messages so that the words on paper match what is said, as well as actions, policies and plans. Credible communication is clear, not ambiguous or prone to exaggeration (Boohar 1999). For example, a participant in a workshop was preparing to meet a new client when she read the client's case history and noted that a client worked at a 'porn shop'. When she later interviewed the client she realised that she actually worked in a 'pawn shop'. Authors can appear to lack credibility when their writing is poor.

In the following example, we ask students to review an article on the Australian Black Saturday bushfires of 2009 when 173 people were killed. The article draws attention to the poor communication used by the Fire Authority in warning people about the dangers of the fires. We use this as a trigger for students to consider how social work values and principles can influence written communication while inviting students to take a reflective and mindful approach to writing and practice technical writing skills.

AIM: (i) to highlight how social work values and principles can influence written communication, (ii) to invite students to take a reflective and mindful approach to writing, and (iii) practice technical writing skills.

Read Don Watson's critique of language used by Fire Authority managers in the 2009 Australian Black Saturday bushfires (http://www.smh.com.au/opinion/society-andculture/language-like-this-should-be-put-to-the-torch-20090918-fv9x.html)

How can these phrases be expressed more simply: 
- $\quad$ "Populating the template"

- $\quad$ "Communicate the degree of the circumstance"

- "Messaging"

What might be some implications of using jargon in the human services?

- How would mindfulness of the following values and principles have influenced you if you were a Fire Authority Manager?

Reflexivity. Reflexivity is the ability to locate yourself in the picture, to understand, and factor in how what you see is influenced by your own way of seeing, and how your very presence influences the situation in which you are placed (Fook 1999). Reflexivity is essential to social work practice as it ensures that we practice in a manner that is consistent with our values and ethics, being aware of the impact we have on others. Writing reflexively explores not only what the experience was, but considers the meaning the writer attached to it both at the time and subsequently, and how this meaning may influence practice in the future (Coles \& Dunworth 2009). Falk and Ross (2001) advocate reflective writing to discover your "self" and connections between ideas, feelings and memories of experience. We do this in our course by asking students to complete the following exercise:

Maintain a personal research diary about one of your university subjects for four weeks. Regularly record your thoughts, feelings as well as events and processes that occur over the period. At the end of four weeks, analyse your diary entries:

- What do your diary entries say about your values and social and cultural position?

- Are any of the ideas you recorded contradictory or inconsistent? Why might this be?

- Think about someone else in your class. How may they have reacted to the same events and processes? 
- What have you learnt about yourself through this process?

- How might you have changed your entries to improve your learning?

Authenticity. Social work educators define authenticity as "the sharing of self by relating in a natural, sincere, spontaneous, open and genuine manner” (Hepworth et al. 2010. p. 107). Similarly, writing with authenticity is also about being yourself. It has been described as

"Writing with your own true voice. Writing that is personal and human, unique to you, reflecting your experience. Writing with clarity and simplicity to allow your readers to learn who you are and who you're being” (Patterson 2012).

We provide students with an example from practice regarding a social worker who was keen to impress his colleagues and consequently described an upcoming presentation in verbose language, resulting in a lack of attendance at the presentation. We ask students to consider how the description of that event could have been written differently and more authentically:

A social worker recently returned to work in Australia after volunteering in an AIDS hospice in Burma. He was asked to prepare a presentation for his colleagues on the experience. Prior to the presentation, he sent out an email to all staff briefly describing the content of the presentation and inviting them to come along. In his email he used long formal sentences and large, important-sounding statements about politics in Burma and community development theory. However, the social worker's actual experience was in people's homes and he had little contact with the political machinations of the country. Not many people attended the presentation, as they were put off by the tone the email. Those who did were rewarded by engaging and moving stories about real-life in Burma and many were motivated to discover more about the country. 
- What kind of email would have produced a better outcome?

Sensitivity. Writing with sensitivity is about being able to see the world from the viewpoints of others. When things are written down, they can become defining. This principle is particularly important for social workers conveying confidential information for multiple audiences, including the client and their family: “To be effective social workers must be exquisitely sensitive to the experiences and feelings of those they try to help and able to describe these experiences and feelings” (Falk \& Ross 2001, p. 4). Thus, language needs to be used sensitively to avoid labelling, stereotyping and cultural or other bias. To encourage students to write sensitively we provide them with the following exercise to trigger their ideas and thinking about report writing, while inviting them to reflect on what they would write jointly with another student.

A child safety caseworker is concerned that a mother who is a newly arrived refugee is not motivated to reunite with her children because she misses her visits with the children and has not attended counseling sessions. The mother confesses that she is afraid that the caseworker will turn her over to immigration authorities.

- What sensitivities will the case worker need to be aware of when writing up her report?

- Expand on this case study to develop a cases history detailing the client's past and present circumstances

- Swap case histories with your classmate

Read your classmate's case history and identify any insensitivities from the point of view of the children, and then the mother.

Purpose and persuasion. The purpose and direction of social work comes from its value systems. Purposeful practice means deliberately acting in accordance with the values and purpose of the profession. Social workers must make sure what they write relates to the 
purpose of the task. Ovretveits' research (in Cumming et al. 2007) found that much of social work recording is irrelevant to task and purpose. For example, an incident was recounted to the research team about a newly employed social worker at a Migrant Resource Centre who wrote a letter of introduction to clients that focused on his hobbies and interests. The letter did not indicate that he had formal qualifications, or a background in supporting people who had been through trauma, or had the capacity to understand and work with cultural differences. Had the letter been sent out unedited, clients would have being wary of the new staff member and unclear about who he was.

Writers, particularly when writing for busy people, must concisely state pertinent facts without commenting on irrelevant issues. Unnecessary, purposeless verbiage creates a barrier to communication. Straying from the issue, inserting personal opinions, using pompous language or rambling about superfluous details, leads the reader to quickly lose interest and the client loses out (Dunlap 1997). "It is bad manners to give (readers) needless trouble ... It is bad manners to waste their time. Therefore brevity . . . then clarity... and how is clarity to be achieved? Mainly by taking trouble; and writing to serve people rather than to impress them” (Lucas 1955, p. 51-59).

Social work writing also seeks to persuade. The ability to exercise influence through persuasion is important in the human services. Funding bodies must be persuaded to invest in programs; legislative and policy making bodies need to be persuaded to establish workable programs; community agencies must be persuaded to refer clients; community members may need to be persuaded to serve as volunteers; and so on. "The process of persuasion involves your presenting good reasons to people for a specific choice among probable alternatives” (Larson, cited in Simons 2008, p. 244).

Persuasive writing is effectively communicating these good reasons. It involves using principles such as emphasising advantages or rewards, being readily understood, showing 
compatibility of values and so on (Simons 2008). Lucas (1955) sees all writing as being strategic, "Just as the art of war largely consists of deploying the strongest forces at the most important points, so the art of writing depends a good deal on putting the strongest words in the most important places” (p. 212). If used ethically, persuasive writing is not about trickery or manipulation, but about targeting information for a client-centred result. The following exercise is used with students to invite them to think about how they would engage in writing in practice in a purposeful, persuasive manner for the best outcomes of the client.

A social worker's client was at risk of homelessness and desperately in need of public housing assistance. The social worker wrote to an officer in the Department of Housing to persuade the Departmental officer to move her client higher up on the public housing waiting list. In writing the letter, the social worker took an adversarial approach, beginning with a criticism of the government for the lack of availability of housing support, and then wrote generally about her client's situation without referring to the key criteria for public housing. The Departmental officer reading the letter was unable to discern the specific reasons the client needed special consideration, and was antagonized by the tone. She sent a form letter in response.

- What is the purpose of the social workers letter?

- What types of information should the social worker have included to make her letter more persuasive and achieve her purpose?

- How can the tone of writing affect its persuasiveness?

\section{Conclusion}

Social workers come to their profession for a range of reasons: to pursue social justice; right wrongs; and to mediate, support, advocate, and reform. In this paper, we argue that ethical professional writing by social workers is client-centred and thus an essential tool of practice. This requires social workers to integrate three core elements when writing: reflective 
mindfulness on their responsibilities; putting into practice their social work values and principles as expressed in codes of ethics; and achieving technical competence in their compositional skills.

We argue that focusing alone on technical writing skills is insufficient for engaging students in recognising the value of good writing. Instead, we need a renewed approach to teaching current and future generations of social work students the reflective art of ethical writing. Students must be engaged first, to recognise writing as an effective tool for social work values and ethics; second, they must be enticed to take a reflective mindful approach to their work consistent with their practice; and third, they must practice sound technical writing skills in the pursuit of good client outcomes. By using exercises that integrate these three elements, social work students are taught to recognise the complex inter-relationships between values, principles and competent writing skills, while providing avenues for practicing good writing. In this way, we improve our prospects for the pursuit of client rights and the betterment of the social work profession. 


\section{References}

Adamek, M. E. (2011) 'Scholarly writing as a tool for empowering change agents in Ethiopia', Reflections: Narratives of Professional Helping, vol. 17, no. 1, pp. 96-101. Adler, G., Alfs, D., Greeman, M., Manske, J., McClellan, T., O'Brien, N., et al. (1993). Social work practitioners as researchers: Is it possible? Social Work in Health Care, 19(2), 115-127.

Alter, C. \& Adkins, C. (2001) 'Improving the writing skills of social work students', Journal of Social Work Education, vol. 37, no. 3, pp. 493-505.

Alter, C. \& Adkins, C. (2006) 'Assessing student writing proficiency in graduate schools of social work', Journal of Social Work Education, vol. 42, no. 2, pp. 337-354.

Aotearoa New Zealand Association of Social Workers (ANZASW) (2008) Chapter 3 The Code of Ethics of ANZASW. Aotearoa New Zealand Association of Social Workers: Social Work Practice. Viewed 16 September 2012, http://anzasw.org.nz/social_work_practice/topics/show/157-background-of-the-codeof-ethics

Arum, R. \& Roksa, J. (2011) Academically adrift: Limited learning on college campuses, University of Chicago, Chicago. Electronic resource: accessed online 14 September, 2012.

Australian Association of Social Workers (AASW) (2010) AASW Code of Ethics 2010. AASW, Canberra, Australia.

Australian Government Senate Community Affairs References Committee (2012) The Commonwealth Contribution to Former Forced Adoption Policies and Practices. Senate Printing Unit, Parliament House, Canberra, Australia: retrieved from http://www.aph.gov.au/Parliamentary_Business/Committees/Senate_Committees?url = clac_ctte/comm_contrib_former_forced_adoption/index.htm 
Banks, S. (2008). 'Critical commentary: social work ethics’. British Journal of Social Work, vol. 38, no. 6, pp. 1238-1249.

Bender, K. \& Windsor, L. C. (2010) 'The four Ps of publishing: Demystifying publishing in peer-reviewed journals for social work doctoral students', Journal of Teaching in Social Work, vol. 30, no. 2, pp. 147-158. doi: 10.1080/08841231003697999

Berlin, S. B. (2005) 'The value of acceptance in social work direct practice: A historical and contemporary view’, Social Service Review, vol. 79, no. 3, pp. 482-510.

Booher, D. (1999) ‘Credibility matters’, The American Salesman, vol. 44, no. 4, pp. 3-5.

British Association of Social Workers (BASW) (2012) The Code of Ethics for Social Work: Statement of Principles. The Policy, Ethics and Human Rights Committee, BASW. Retrieved from http://cdn.basw.co.uk/upload/basw_112315-7.pdf

Canadian Association of Social Workers (CASW) (2005) Code of Ethics, Canadian Association of Social Workers. Viewed 16 September 2012, http://www.caswacts.ca/en/what-social-work/casw-code-ethics

Carney, D. \& Koncel, M. A. (1994) 'Efficacy in social work writing’. Paper presented at the Annual Meeting of the Conference on College Composition and Communication, Nashville, March 16-19.

Coles, M. \& Dunworth, M. (2009) ‘Reflexive/reflective writing’, Practice Learning Qualifications, Scottish Social Services Council. Viewed 10 February 2012, http://creativecommons.org/licenses/by-nc/2.5/scotland/

Cumming, S., Fitzpatrick, E., McAuliffe, D., McKain, S., Martin, C. \& Tongea, A. (2007) 'Raising the Titanic: Rescuing social work documentation from the sea of ethical risk', Australian Social Work, vol. 60, no. 2, pp. 239-257. 
Cuthbert, D. \& Spark, C. (2008) 'Getting a GRiP: Examining the outcomes of a pilot program to support graduate research students in writing for publication', Studies in Higher Education, vol. 33, no. 1, pp. 77-88. doi: 10.1080/03075070701794841

D'Cruz, H. (2004) Constructing meanings and identities in child protection practice, Tertiary Press, Croydon, Australia.

Dunlap, K. (1997) 'Write on! Practical suggestions for preparing social work records’, The New Social Worker, vol. 4, no. 4, online resourced retrieved from http://www.socialworker.com/writeon.htm

Ellman, A., Rothstein, A., Rubinstein, H. \& Vinnik, E. (2012) 'Write on! Writing for social justice’, New York Collective of Radical Educators, Accessed 26 October 2012 from www.nycore.org/2012/06/write-on-writing-for-sj/

Epple, D. M. (2010) 'The experiences of St Francis: Parallels for Christian social workers', Social Work and Christianity, vol. 37, no. 1, pp. 78-92.

Falk, D. S. \& Ross, P. G. (2001) ‘Teaching social work writing: An integrative approach’, The Journal of Baccalaureate Social Work, vol. 6, no. 2, pp. 125-41.

Fook, J. (1999) 'Reflexivity as method’, Health Sociology Review, vol. 9, no. 1, pp. 11-20.

Fouché, C., \& Lunt, N. (2009) 'Using groups to advance social work practice-based research', Social Work With Groups, vol. 32 no. 1, pp. 47-63. doi: 10.1080/01609510802314659

Gambrill, E. (2001) ‘Social work: An authority-based profession’, Research on Social Work Practice, vol. 11, no. 2, pp. 166-175.

Gelman, S. (1992) 'Risk management through client access to case records’, Social Work, vol. 37, no. 1, pp. 73-79.

Glicken, M. D. (2008) A Guide to Writing for Human Service Professionals, Rowman and Littlefield, Maryland. 
Gray, M., Plath, D. \& Webb, S. (2009) Evidence-Based Social Work: A Critical Stance, Routledge, London.

Harper K. \& Lantz J. (1996) .Cross-cultural practice: Social work with diverse populations. Chicago: Lyceum Books

Healy, K. \& Mulholland, J. (2007) Writing Skills for Social Workers, Sage Publications Ltd, London, UK.

Hepworth, D. H., Rooney, R. H., Rooney, G. D. (2010) Direct Social Work Practice: Theory and Skills, Cengage Learning, Belmont.

Heron, G. \& Murray, R. (2004) 'The place of writing in social work: Bridging the theorypractice divide', Journal of Social Work, vol. 4, no. 2, pp. 199-214.

Hugman, R. (2005). Exploring the paradox of teaching ethics for social work practice. Social Work Education, vol. 24, no. 5, pp. 535-545.

Human Rights and Equal Opportunity Commission (HREOC) (1997) Bringing Them Home: Report of the National Inquiry into the Separation of Aboriginal and Torres Strait Island Children from Their Families 1997, Commonwealth of Australia, Australia.

International Federation of Social Workers (IFSW) (2004) Statement of Ethical Principles, International Federation of Social Work. Viewed 16 September, 2012, http://ifsw.org/policies/statement-of-ethical-principles/

Lucas, F. L. (1955) Style: The Art of Writing Well, Cassell, London.

Luiselli, J. K. (2010) 'Writing for publication: A performance enhancement guide for the human services professional’, Behavior Modification, vol. 34, no. 5, pp. 459-473. doi: 10.1177/0145445510383529

Malekoff, A. (1999) 'A practitioner's journey to becoming a writer', Families in Society: The Journal of Contemporary Human Services, vol. 80, no. 2, pp. 190-194. 
Malekoff, A. (2006) 'Putting ideas to paper: A guideline for practitioners (and others) who wish to write for publication', Social Work With Groups, vol. 29, no. 2, pp. 57-72. doi: 10.1300/J009v29n02_05

McAuliffe, D. (2014). Interprofessional ethics: Collaboration in the social, health and human services. Port Melbourne, Australia: Cambridge University Press.

McAuliffe, D. \& Chenoweth, L. (2008) 'Leave no stone unturned: The inclusive model of ethical decision making', Ethics and Social Welfare, vol. 2, no. 1, pp. 38-49.

Miller, T.P. (1991) 'Treating writing as a social praxis', Journal of Advanced Composition, vol. 11 , no. 1 , pp. 57-72.

Naiburg, S (2003) 'Mentors at the gate: Editors talk about clinical writing for journal publication', Clinical Social Work Journal, vol. 31, no. 3, pp. 295-313.

National Association of Social Workers (NASW) (2008) Code of Ethics, NASW Press, Washington, DC.

Oglensky, B. D. \& Davidson, E. J. (2009) 'Teaching and learning through clinical reportwriting genres', The International Journal of Learning, vol. 16, no. 9, pp. 139-152.

Oxford English Dictionary Oxford Dictionaries, viewed 10 February 2012, http://oxforddictionaries.com/

Patterson, J. (2012) Confident Writing, viewed 10 February 2012, www.confidentwriting.com Reamer, F. (2012). Essential ethics education in social work field instruction: A blueprint for field educators, Field Educator, vol. 2, no. 2, pp. 1-15.

Reynolds, J. F., Mair, D. C., \& Fishcer, P. C. (1992) Writing and Reading Mental Health Records, 2nd Edition, Sage Publications, Newbury Park.

Sennett, R. (2003) Respect in a World of Inequality. New York: W. W. Norton. 
Simon B. L. \& Soven, M. (1990) 'The teaching of writing in social work education: A pressing priority for the 1990s', Journal of Teaching in Social Work, vol. 3, no. 2, pp. 47-63.

Simons R. L. (2008) 'Generic social work skills in social administration', Administration in Social Work, vol. 11, no. 3-4, pp. 241-254.

Solomon, F. (2004) 'Words on words', Policy and Practice, vol. 62, no. 3, pp. 31.

Spigelman, C. \& Grobman, L. (2006) 'Why we chose rhetoric: Necessity, ethics and the (re)making of a professional writing program', Journal of Business and Technical Communication, vol. 20, no. 1, pp. 48-64.

Staudt, M. M., Dulmus, C., \& Bennett, G. A. (2003) 'Facilitating writing by practitioners: Survey of practitioners who have published', Social Work, vol. 48, no. 1, pp. 75-83.

Steinberg, D. M. (2007) 'From paper to publication: Passing on some tips', Social Work With Groups, vol. 30, no. 2, pp. 41-55.

Thyer, B. A. (2008) Preparing research articles, New York: Oxford University Press.

Waller, M. A., Carroll, M. M. \& Roemer, M. (1996) 'Teaching writing in social work education’, Journal of Teaching in Social Work, vol. 13, no. 1-2, pp. 43-56.

Williams, L. F., \& Hopps, J. G. (1987) 'Publication as a practice goal: Enhancing opportunities for social workers', Social Work, vol. 32, no. 5, pp. 373-376.

Wronka, J. (2008) Human rights and social justice: Social action and service for the helping and health professionals, Thousand Oaks, CA: Sage. 